\title{
BMJ Open Pilot for the Australian Breast Device Registry (ABDR): a national opt-out clinical quality registry for breast device surgery
}

\author{
Ingrid Hopper, ${ }^{1}$ Renee L Best, ${ }^{1}$ John J McNeil, ${ }^{1}$ Catherine M Mulvany, ${ }_{1}^{1}$ \\ Colin C M Moore, ${ }^{2,3}$ Elisabeth Elder, ${ }^{4,5}$ Marie Pase, ${ }^{1}$ Rodney D Cooter, ${ }^{1,6,7}$ \\ Sue M Evans ${ }^{1}$
}

To cite: Hopper I, Best RL, McNeil JJ, et al. Pilot for the Australian Breast Device Registry (ABDR): a national opt-out clinical quality registry for breast device surgery. BMJ Open 2017;7:e017778. doi:10.1136/ bmjopen-2017-017778

- Prepublication history for this paper is available online. To view these files, please visit the journal online (http://dx.doi org/10.1136/bmjopen-2017017778).

RDC and SME contributed equally.

Received 16 May 2017 Revised 15 August 2017 Accepted 26 September 2017

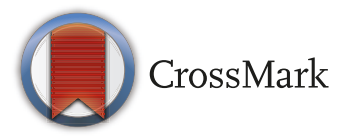

For numbered affiliations see end of article.

Correspondence to Dr Ingrid Hopper; ingrid.hopper@monash.edu

\section{ABSTRACT}

Purpose To establish a pilot clinical quality registry (CQR) to monitor the quality of care and device performance for breast device surgery in Australia.

Participants All patients having breast device surgery from contributing hospitals in Australia. A literature review was performed which identified quality indicators for breast device surgery.

Findings to date A pilot CQR was established in 2011 to capture prospective data on breast device surgery. An interim Steering Committee and Management Committee were established to provide clinical governance, and guide quality indicator selection. The registry's minimum dataset was formulated in consultation with stakeholder groups; potential quality indicators were assessed in terms of (1) importance and relevance, (2) usability, (3) feasibility to collect and (4) scientific validity. Data collection was by a two-sided paper-based form with manual data entry. Seven sites were recruited, including one public hospital, four private hospitals and two day surgeries. Patients were recruited and opt-out consent used.

Future plans The pilot breast device registry provides high-quality population-based data. It provides a model for developing a national CQR for breast devices; its minimum dataset and quality indicators reflect the opinions of the broad range of stakeholders. It is easily scalable, and has formed the basis for other international surgical groups establishing similar registries.

\section{INTRODUCTION}

Breast devices, incorporating breast implants and breast tissue expanders, are implanted under the breast tissue or chest muscle to form or improve the shape of a breast. ${ }^{1}$ The majority of individuals undergoing surgery are young women. The Australian Institute of Health and Welfare determined that 27600 breast devices were implanted during the 12-month period between July 2014 and June 2015, ${ }^{2}$ a $24 \%$ increase in primary breast implant procedures from the previous year.
Strengths and limitations of this study

- We outline the approach taken to establish a clinical quality registry (CQR) for breast device surgery, including the establishment of governance, a minimum dataset, quality indicators, data completeness and reporting framework. This will assist other researchers developing their own CQR.

- This is the first opt-out CQR for breast device surgery to have breast surgeons, cosmetic surgeons and plastic and reconstructive surgeons contributing data. This model has become the model registry for several other collaborating countries.

- The lack of a nationally recognised ethics approval process in Australia is a major impediment for national roll out.

Approximately $80 \%$ of devices are implanted for cosmetic purposes, about $17 \%$ of surgeries are performed to reconstruct the breast post mastectomy and $3 \%$ to correct congenital anomalies. ${ }^{2}$ Implants are not considered to be lifetime devices, and it is estimated that at least $30 \%$ of annual implant procedures in Australia are revisions of previous implants. ${ }^{2}$ As these are 'known' or expected complications, there is no requirement from the Australian regulator, the Therapeutic Goods Administration (TGA), for clinicians to report or record these revision operations as an adverse effect or incident. This represents a lost opportunity to gather data which can inform either short-term or long-term device safety, as an increased rate of adverse events (such as rupture) may indicate a problem with the breast device or with the surgical technique used for implanting it.

Breast implants have been associated with a number of high-profile health scares in the past. In the 1980 s, it was suggested that 'silicone' breast implants were linked to 
cancer, connective tissue disease, offspring defects and neurological disease. ${ }^{3}$ Over 12000 individual law suits were filed against breast implant manufacturer Dow Corning, ${ }^{4}$ leading to compensation payments totalling US $\$ 3.2$ billion. Lack of objective scientific data on clinical outcomes related to silicone implants allowed anecdotal impressions to gain traction, strengthening in 1996 when laboratory studies suggested silicone gel could provoke an immune response in animals ${ }^{5-7}$ and leading to the formation of several breast implant registries. Although epidemiological evidence has since proven these concerns to be unfounded, breast implant safety has remained controversial. ${ }^{38-10}$

The well-publicised Poly Implant Prothèse (PIP) crisis brought these issues to prominence again. ${ }^{11}$ In 2010, the French manufacturer of these implants was found to be substituting approved medical grade silicone with unapproved silicone gel. In response, regulatory bodies recalled the unsold implants, and several countries including France, Germany and Sweden recommended a programme of explantation. Also reported the same year was emerging evidence suggesting an association between breast implants (both silicone and saline filled) and anaplastic large cell lymphoma (ALCL), ${ }^{12}$ and a cohort study of polyurethane-coated breast implants suggested a link to breast cancer. ${ }^{13}$

These issues highlighted the urgent need for well-designed breast device registries. The existing registries failed to answer any questions arising out of the PIP crisis, and indeed it was extrapolated that only $3.4 \%$ of known PIP implants were captured in the Australian registry at the time. ${ }^{10}$ An Australian Senate Inquiry into the PIP implants crisis recommended the establishment of a national opt-out registry for breast device surgery. ${ }^{14}$ We describe the development of this pilot national clinical quality registry (CQR) for breast devices in Australia and, here, we report the governance and operation of this registry and some findings to date.

\section{COHORT DESCRIPTION}

A pilot Breast Device Registry (BDR) was established in 2011 in Australia with the objectives of providing early identification of device adverse events, benchmarking performance of clinicians implanting breast devices, providing risk mitigation for manufacturers, allowing immediate responses to safety concerns, patient tracking (by providing a central repository to allow device recall) and facilitating research towards improved patient safety. The new registry was named the Breast Device Registry (BDR), to describe the inclusion of tissue expanders.

\section{Meetings with stakeholders}

In March 2012, a stakeholder meeting was held to discuss governance arrangements and implementation methodology. In principle support was given by all members (table 1).
Table 1 Stakeholder groups engaged throughout the development of the Breast Device Registry

$\begin{array}{ll}\text { Clinical groups } & \begin{array}{l}\text { Australian Society of Plastic Surgeons } \\ \text { Breast Surgeons of Australia and } \\ \text { New Zealand } \\ \text { Australian College of Cosmetic Surgeons }\end{array} \\ \text { Government } & \begin{array}{l}\text { Therapeutic Goods Administration } \\ \text { Department of Health }\end{array} \\ \text { Industry } & \begin{array}{l}\text { Medical Technology Association of } \\ \text { Australia }\end{array} \\ \text { Insurers } & \begin{array}{l}\text { Medical Indemnity Industry Association of } \\ \text { Australia }\end{array} \\ \text { Consumers } & \text { Consumer Health Forum } \\ \text { Academia } & \text { Epidemiologists from Monash University }\end{array}$

\section{Steering Committee}

The BDR governance model was developed in accordance with the Operating Principles for Australian Clinical Quality Registries, ${ }^{15}$ which had been endorsed by Australian Health Ministers in 2010. A Steering Committee was established to identify a minimum dataset, determine methodology for data collection and to form a collaboration with stakeholders, agree on a funding model and develop a governance platform, including a national Steering Committee. The Steering Committee membership comprised clinical governing bodies including those representing plastic surgeons, breast surgeons and cosmetic surgeons, Federal and State Governments including the regulatory sector (TGA), the national association representing companies in the medical technology industry, insurers of devices (product) and surgeons, policy drivers (Medicare) and academics with expertise in epidemiology and clinical registries.

\section{Infrastructural requirements}

Funding

Seed funding was provided by the Australasian Foundation for Plastic Surgery, a not-for-profit organisation that supports quality health outcomes for everyone involved with plastic surgery.

\section{Consent requirements}

The BDR used an opt-out consent model, a key element to large population capture. ${ }^{16}$ All patients receiving surgery involving a breast device at the particular institution were included in the registry. Patients could choose to opt out and remove their data from the registry. On receipt of a completed data collection form, the registry posted an explanatory statement to the patient at the address listed on the form. The explanatory statement used 'plain language' and provided clear details of the process for opting out, including the free call telephone number and email address. The patient had 2 weeks from sending the explanatory statement to opt out, then their details were included in the registry. Opt out could occur later, in which case patient details were removed from the 
database. A total of 34 patients opted out, thus the opt-out rate was $1.75 \%$.

\section{Finding centres to participate}

Hospitals were approached in which Monash University had established registries previously. The initial step in site recruitment was identification of a clinical lead, then submission for ethics approval. Ethics Committees at each site provided approval. Agreement to participate was obtained from each surgeon performing implant surgery at that site. The study methodology was tested at seven pilot sites undertaking breast implant surgery between 26 March 2012 and 31 May 2015. Included were one public hospital in Victoria, one private hospital in each of New South Wales, Victoria, Tasmania and South Australia, and a day surgery in each of South Australia and Western Australia. There was a lower rate of cosmetic surgery (45\%) found in this pilot compared with the expected rate nationally $(80 \%)$, which was anticipated given the inclusion of two day surgeries, where cosmetic operations primarily occur.

\section{Registry development issues}

Inclusion criteria

Any person undergoing surgery involving the insertion or removal of a breast implant or breast tissue expander, reposition of an existing device or surgery on a breast with a device already inserted, at a participating site was eligible for inclusion in the registry, provided that their surgeon had agreed to contribute data to the registry. Patients' eligibility was definitively determined through reference to a list of relevant International Statistical Classification of Diseases and Related Health Problems, Tenth Revision, Australian Modification (ICD-10-AM) codes (table 2).

Procedures are listed in table 2.

\section{Developing quality indicators}

A literature review identified potential quality indicators relating to breast surgery against which the registry might report and the Steering Committee was asked to provide suggestions for possible reporting by the registry. Quality indicators thus identified formed a full ('maximum') list of proposed indicators. This list was discussed with the clinical specialty groups and each indicator then assessed against the following criteria: (1) importance and relevance to clinicians, (2) usability, (3) feasibility to collect and (4) scientific validity. ${ }^{17}$ Table 3 lists the final quality indicators that were selected for collection and evaluation through the pilot project.

\section{Developing the minimum dataset}

Following determination of the quality indicators, a list of data elements to be collected by the BDR was developed, with definitions sourced from the national Metadata Online Data Dictionary where available (table 4). ${ }^{18}$ Where national definitions did not exist, definitions were sought from international registries or from the published literature for review and endorsement by the steering committee. A number of data items were removed
Table 2 The International Statistical Classification of Diseases and Related Health Problems, Tenth Revision, Australian Modification (ICD-10-AM) codes as per the Australian Breast Device Registry data extract and transfer instructions

\begin{tabular}{|c|c|}
\hline \multicolumn{2}{|c|}{ Breast Surgery ICD-10 AM codes } \\
\hline $45524-00$ & Augmentation mammoplasty, unilateral. \\
\hline 45528-00 & Augmentation mammoplasty, bilateral. \\
\hline 45527-00 & $\begin{array}{l}\text { Augmentation mammoplasty, following } \\
\text { mastectomy, unilateral. }\end{array}$ \\
\hline $45527-01$ & $\begin{array}{l}\text { Augmentation mammoplasty, following } \\
\text { mastectomy, bilateral. }\end{array}$ \\
\hline 45539-00 & $\begin{array}{l}\text { Reconstruction of breast with insertion of } \\
\text { tissue expander. }\end{array}$ \\
\hline 45530-02 & Reconstruction of breast using flap. \\
\hline 45548-02 & $\begin{array}{l}\text { Adjustment of breast tissue expander. } \\
\text { Relocation of breast tissue expander. }\end{array}$ \\
\hline 45548-01 & Removal of breast tissue expander. \\
\hline 45542-00 & $\begin{array}{l}\text { Removal of breast tissue expander and } \\
\text { insertion of permanent prosthesis. }\end{array}$ \\
\hline 45548-00 & $\begin{array}{l}\text { Removal of breast prosthesis. } \\
\text { Includes capsulotomy. } \\
\text { Excision of fibrous capsule. } \\
\text { Excludes that with replacement } \\
\text { (capsulectomy). }\end{array}$ \\
\hline $45552-00$ & $\begin{array}{l}\text { Replacement of breast prosthesis. } \\
\text { Includes: capsulotomy. } \\
\text { Excision of fibrous capsule. } \\
\text { Formation of new pocket. }\end{array}$ \\
\hline
\end{tabular}

because they were considered (a) subjective-grading of capsular contracture and ptosis, (b) poorly collected at the time of operation-patient characteristics such as height, weight, skin type or (c) ambiguous and liable to cause confusion-previous breast surgery. All stakeholder groups assisted in developing the final minimal dataset.

\section{Developing the data collection form}

Data were collected at the time of surgery via a short 'tick and stick' process. Retrospective data collection was not possible as many of the required data elements, such as operative technique, were poorly documented in hospital medical records. Patient identifiers were collected for future contact for patient-reported outcomes, or in the event of a safety issue. Data were initially captured via a paper data collection form while the data elements were being tested. Two paper forms were developed: one for primary and one for revision surgery. The pilot identified that having two data collection forms was confusing for theatre staff. This was particularly so in situations where it was unclear whether a single surgical event could be understood as primary or revision, for example, removal of a tissue expander and insertion of an implant. These forms were condensed to a single, double-sided form.

Commentary on the form was provided by device supplier representatives, as well as surgeons and theatre 
Table 3 Quality indicators selected to be tested by the Breast Device Registry

\begin{tabular}{lll} 
Outcome measures & Structural indicators & Predictor variables \\
\hline Rate of symptomatic revision & Site type (public/private) & Device selection: brand, design \\
Rate of symptomatic revision due to & characteristics, for example, shell, fill, texture. \\
infection & & Indication for surgery: augmentation, \\
Rate of symptomatic revision due to & reconstruction. \\
capsular contracture & Surgical technique: drains, plane, antibiotic \\
Risk-adjusted mortality rate & & use, dipping. \\
\hline
\end{tabular}

nurses participating in the pilot. The latter occurred during a formal orientation to the registry procedures, which allowed surgeons and theatre staff to discuss the registry with the BDR custodian and for the team to customise the proposed data collection methodology. The completed data collection forms were sent to the registry custodian monthly by overnight post for data entry. The data were then entered using a manual entry system into a database that was developed at Monash University.

\section{Data completeness}

For this pilot, data were not imputed if missing, and a data element was considered complete if data were entered into the data field. A data completeness audit showed that patient demographics, mostly provided using the patient sticker, had high capture rates with the exception of email addresses, which were rarely provided (table 5). The low collection rates of email addresses will prevent the registry from using this as a way to capture outcome data unless strategies can be implemented in clinical information systems to improve this situation. Device and operation information were captured at over $90 \%$ completion. The section recording reasons for revision had lower capture rates. Feedback from hospital staff and Steering Committee members regarding the low rates of completion for the reason for revision details included: these details are within the last section of the doublesided collection form (form fatigue), or that the clinician completing the form may not be the surgeon and may not know the answer to the question, and/or interpretation issues. Reconciliation against medical records was not possible as much of the data on the BDR data collection form were not duplicated in the medical record.

Surgeons suggested a tablet computer be used in the operating theatre to facilitate data capture and potentially improve completeness rates and data accuracy. An electronic data collection application that can be accessed by any device is under development, which will have in-built validation rules (such as mandatory fields) and adaptive responses such that only questions relevant to that operation will be posed. It is expected to improve data completeness, accuracy and ease of collection. As part of this database, there is scope for the registry to use bar code scanning which is in accordance with GS1 data standards to retrieve information related to device characteristics captured in the registry (shell, fill, shape) which can reduce the burden on data entry personnel. GS1 data standards provide unique, unambiguous product identifiers. $^{19}$

\section{Case ascertainment}

Two Victorian hospitals sent a monthly extract of demographic and treatment information including ICD-10-AM codes to the registry custodian by a secure file transfer process for all patients undergoing breast device surgery. Case ascertainment was assessed by matching data collection forms against the operating records from hospitals. From a total of 206 patients, there were six patients for whom the hospital recorded breast implant surgery but for whom no case report form was provided, thus

\section{Table 4 Breast Device Registry minimum dataset}

Identifiers Demographic details: patient identifiers including contact person information.

Device details: device batch identifiers; manufacturer; and distributor.

Site details: identifying physically separate operating theatres, via name and address.

Surgeon details: name of primary operating surgeon.

Additional Patient history: reason for primary operation; description of the operation; previous radiotherapy.

factors Elements of operation: incision site; plane; mastopexy; use of mesh or acellular dermal matrix; use of fat grafting; tissue expander intraoperative fill volume.

Additional intraoperative techniques: antiseptic rinse; antibiotic solution; prophylactic antibiotics; drains; sleeve/ funnel (Keller funnel); nipple guards; glove change for insertion.

Revision operation details: description of operation; capsulectomy.

Complications causing or found during revision surgery: removal of PIP; removal of overseas implant; device rupture; device deflation; capsular contracture; silicone extravasation; device malposition; skin scarring problems; deep wound infection; seroma/haematoma; breast cancer; anaplastic large cell lymphoma. 
Table 5 Data items included in the minimum dataset and completeness of data capture

\begin{tabular}{|c|c|}
\hline Data item & Completeness \\
\hline \multicolumn{2}{|l|}{ Patient demographic } \\
\hline Patient Medicare number & $97 \%$ \\
\hline Patient address & $100 \%$ \\
\hline Patient phone numbers & $70 \%$ \\
\hline Patient email & $3 \%$ \\
\hline Patient Date of Birth & $100 \%$ \\
\hline Patient surname and first name & $100 \%$ \\
\hline \multicolumn{2}{|l|}{ Operation } \\
\hline Operation date & $98 \%$ \\
\hline \multicolumn{2}{|l|}{ Device } \\
\hline Device identifier & $99 \%$ \\
\hline Mesh dermal sheet & $82 \%$ \\
\hline \multicolumn{2}{|l|}{ Patient history } \\
\hline Category of operation & $96 \%$ \\
\hline Operation type/device operation type & $99 \%$ \\
\hline Previous radiotherapy & $90 \%$ \\
\hline \multicolumn{2}{|l|}{ Elements of operation } \\
\hline Incision site & $95 \%$ \\
\hline Plane & $90 \%$ \\
\hline Concurrent mastopexy/reduction & $83 \%$ \\
\hline Concurrent flap cover & $82 \%$ \\
\hline Fat grafting & $76 \%$ \\
\hline $\begin{array}{l}\text { If tissue expander, intraoperative fill volume } \\
\text { completed }\end{array}$ & $88 \%$ \\
\hline \multicolumn{2}{|l|}{ Intraoperative techniques } \\
\hline Operations with intraoperative techniques & $94 \%$ \\
\hline \multicolumn{2}{|l|}{ Revision details } \\
\hline Revision type & $83 \%$ \\
\hline Capsulectomy & $86 \%$ \\
\hline Reason for revision & $83 \%$ \\
\hline Removing a PIP implant & $86 \%$ \\
\hline Removal of implant inserted overseas & $79 \%$ \\
\hline Device rupture & $85 \%$ \\
\hline Silicone extravasation found in device rupture & $80 \%$ \\
\hline Device deflation & $57 \%$ \\
\hline Capsular contracture & $68 \%$ \\
\hline Device malposition & $63 \%$ \\
\hline Skin scarring problems & $59 \%$ \\
\hline Deep wound infection & $60 \%$ \\
\hline Seroma/haematoma & $58 \%$ \\
\hline Breast cancer & $58 \%$ \\
\hline Anaplastic large cell lymphoma & $52 \%$ \\
\hline
\end{tabular}

PIP, Poly Implant Prothèse.

the capture rate was determined to be $97 \%$. From this pilot, it was determined that case ascertainment audits with each individual hospital was deemed too costly and resource intensive. Matching registry records with state-wide databases is currently being explored. Sales data reflecting the total number of implants released by manufacturers may also be used as the denominator. The work towards ensuring near $100 \%$ data completeness and case ascertainment rates is now paramount as we begin to develop the reports that will be benchmarked and used to improve quality of care.

\section{Outcome measures \\ Reporting framework}

Systematic and complete capture of data managed by registry experts and analysed by statisticians using appropriate risk adjustments are an essential part of the feedback loop to both implanters (clinicians) and manufacturers of the devices. The reporting framework is designed to comply with the National Operating Principles for Clinical Quality Registries. ${ }^{15}$ Aggregate reports will be available to hospital executives on institutional performance on quality indicators, with other institutions' results provided for blinded comparison. Individual surgeons will be able to access their own results, and will be provided with individual reports. Device performance will be reported, with other devices' results used for blinded comparison, and will be available to industry. An annual report on quality indicator outcomes will also be published and available to the public. An escalation policy will be developed in consultation with clinicians and health services.

\section{Device performance}

Complication rates relating to specific devices will be monitored as time series and as a static display each 6 months. A surveillance system will trigger a signal of possible excess complication rates for a certain device, and a plan for subsequent follow-up of any such trigger. In the first instance, it is likely that a difference of $2 \mathrm{SD}$ from the expected revision rate will trigger a review of the data. However, a comprehensive action plan to decide upon the rate of revision due to failure reportable to the TGA will be developed in consultation with biostatisticians.

\section{Institution and clinician performance}

It is expected that the respective colleges will manage clinician performance concerns, either the Royal Australasian College of Surgeons or the Australasian College of Cosmetic Surgery. Each College has policies and processes for managing performance issues, including mentoring and disciplinary action. Details of the communication and action plan for devices, hospitals and clinicians will be based on a risk assessment from the registry data.

\section{Follow-up}

Patient reported outcome measures will be collected via individual contact at $1,2,5$ and 10 years. Currently available patient-reported outcome measures ${ }^{20}$ have been shortened for use by the registry, and will be collected using a web-enabled database capable of collecting patient data electronically, which sends a secure survey link by text message to mobile phones. Regular record 
linkage is planned to link registry patients with routinely collected data from cancer registries including the breast quality audit, the national death registry and hospital discharge records.

\section{Collaboration}

Opportunities for a collaborative network of breast device registries are being pursued internationally through the International Collaboration of Breast Registry Activities (ICOBRA).$^{21}$ We are sharing the methodology internationally, which can be accessed by joining ICOBRA. Work is currently being undertaken to harmonise an internationally agreed upon core minimum dataset and data definitions which will be collected by all contributing breast implant registries. This will enable amplification of the dataset to provide greater evidence of the safety and quality of care provided for patients receiving breast implants worldwide.

\section{Strengths and limitations}

The strengths of this pilot are that it was the first of its type internationally to have breast surgeons, cosmetic surgeons and plastic and reconstructive surgeons contributing data, and that it has become the model registry for several other collaborating countries. Preliminary evaluation at seven sites has determined that both the governance process and data capture tools are acceptable.

The lack of a nationally recognised ethics approval process in Australia is a major impediment to national roll out of this important government-supported safety initiative. Substantial time delays and financial impost are associated with such ethics hurdles, ${ }^{22}$ giving individual institutions the means to obstruct the path to better patient safety. This hampers Australia's capacity as an international leader in registry science compared with other countries in which medical ethical approval is obtained nationally, such as the Netherlands and Sweden. ${ }^{23}$ It is imperative that a nationally recognised ethics approval for clinical quality registries is developed for Australia. ${ }^{24}$

\section{CONCLUSION}

The pilot BDR provided high-quality population-based data and a model for developing a national CQR for breast devices. Its minimum dataset and quality indicators reflect the opinions of the broad range of stakeholders. It is easily scalable, and has formed the basis for other international surgical groups establishing similar registries. It was estimated from data provided by industry (commercial-in-confidence) that an Australian registry would need to recruit approximately 300 implanting sites to obtain population coverage. In 2015, a report of the Independent Review of Medicines and Medical Devices Regulation made 58 recommendations including that all high-risk implantable devices be included in a registry to perform postmarketing monitoring of adverse events. This, supported by the success of the pilot study, acted as an impetus for the Australian Government committing funding over a 3-year period in order to expand the registry to a national scale. The Australian Breast Device Registry is a Commonwealth Government initiative tracking the outcomes and quality of all breast device surgeries performed across Australia.

\section{Author affiliations}

${ }^{1}$ Department of Epidemiology and Preventive Medicine, School of Public Health and Preventive Medicine (SPHPM), Monash University, Melbourne, Victoria, Australia ${ }^{2}$ Australian Centre for Cosmetic Surgery, Neutral Bay, New South Wales, Australia ${ }^{3}$ Australasian College of Cosmetic Surgery, Parramatta, New South Wales, Australia ${ }^{4}$ Breast Surgeons of Australia and New Zealand (BreastSurgANZ), Randwick, New South Wales, Australia

${ }^{5}$ Westmead Breast Cancer Institute, Westmead Hospital, Westmead, New South Wales, Australia

${ }^{6}$ Australian Society of Plastic Surgeons, St Leonards, New South Wales, Australia ${ }^{7}$ Australasian Foundation for Plastic Surgery, St Leonards, New South Wales, Australia

Acknowledgements We gratefully acknowledge the surgeons who provided feedback from pilot sites and the stakeholder groups who provided input on the development of the pilot registry; device manufacturers and distributors, product insurers, medical indemnity insurers, Federal and State Governments including representatives from the Therapeutic Goods Administration and Medicare. Also collaborating colleagues internationally through the International Collaboration of Breast Registry Activities (ICOBRA) who have surveyed, committed to, and adopted our minimum dataset in the data collection forms and data definitions. Also Arul Earnest for assistance with drafting.

Contributors SME, RDC and JJM contributed to the concept and design of the study. SME, RDC, EE, CCMM, CMM, RLB, MP and IH contributed to the acquisition, analysis and interpretation of the data. SME and RDC wrote the first draft of the protocol. SME, RDC, JJM, EE and CCMM revised the protocol for important intellectual content. All authors have read and approved the final version of the manuscript to be published.

Funding This pilot study was funded by the Australasian Foundation for Plastic Surgery.

\section{Competing interests None declared.}

Ethics approval Ethics approval for this project was obtained from the Human Research Ethics Committees of the Alfred Hospital, Melbourne, to operate the BDR. Ethics approval was also required from each pilot site.

Provenance and peer review Not commissioned; externally peer reviewed.

Data sharing statement The minimum data set is available to share through the International Collaboration of Breast Registry Activities (ICOBRA)

Open Access This is an Open Access article distributed in accordance with the Creative Commons Attribution Non Commercial (CC BY-NC 4.0) license, which permits others to distribute, remix, adapt, build upon this work non-commercially, and license their derivative works on different terms, provided the original work is properly cited and the use is non-commercial. See: http://creativecommons.org/ licenses/by-nc/4.0/

(c) Article author(s) (or their employer(s) unless otherwise stated in the text of the article) 2017. All rights reserved. No commercial use is permitted unless otherwise expressly granted.

\section{REFERENCES}

1. United States Food and Drug Administration. Medical devices, Washington: U.S. Department of Health and Human Services, 2013. http://www.fda.gov/MedicalDevices/default.htm

2. Australian Institute of Health and Welfare. Admitted patient care 2014-15: Australian hospital statistics. Health services series no. 68. Canberra: AlHW, 2016.

3. McLaughlin JK, Lipworth L, Murphy DK, et al. The safety of silicone gel-filled breast implants: a review of the epidemiologic evidence. Ann Plast Surg 2007;59:569-80.

4. Bernstein DE, Angell M. The breast implant fiasco. Calif Law Rev 1999;87:457. 
5. Nicholson JJ, Hill SL, Frondoza CG, et al. Silicone gel and octamethylcyclotetrasiloxane (D4) enhances antibody production to bovine serum albumin in mice. J Biomed Mater Res 1996;31:345-53.

6. Naim JO, Ippolito KM, Lanzafame RJ, et al. Induction of type II collagen arthritis in the DA rat using silicone gels and oils as adjuvant. J Autoimmun 1995;8:751-61.

7. Hill SL, Landavere MG, Rose NR. The adjuvant effect of silicone gel and silicone elastomer particles in rats. Curr Top Microbiol Immunol 1996;210:123-37.

8. Watson R. Europe is updating rules on medical devices after implant fiasco. BMJ 2012;344:e766.

9. O'Dowd A. Europe plans to strengthen surveillance system for medical devices, MPs are told. BMJ 2012;344:e4179.

10. Jeeves AE, Cooter RD. Transforming australia's breast implant registry. Med J Aust 2012;196:232-4.

11. Therapeutic goods administration. PIP breast implants - TGA update canberra: Australian government, 2013. http://www.tga.gov.au/ safety/alerts-device-breast-implants-pip-130211.htm

12. United states food and drug administration. Anaplastic large cell lymphoma (ALCL) In women with breast implants:preliminary FDA findings and analyses, 2011. http://www.fda.gov/MedicalDevices/ ProductsandMedicalProcedures/ImplantsandProsthetics/BreastImpl ants/ucm239996.htm

13. Pan SY, Lavigne E, Holowaty EJ, et al. Canadian breast implant cohort: extended follow-up of cancer incidence. Int J Cancer 2012;131:1148-57.

14. The Department of Health. Australian government response to senate community affairs references committee report on the role of the therapeutic goods administration regarding medical devices, particularly poly implant prothese (PIP) breast implants, 2013. http:// www.health.gov.au/internet/main/publishing.nsf/Content/RPGDBORP-Respons-PIP-breast-implants (accessed 28 Apr 2017)
15. Australian Commission on Safety and Quality in Health Care. Framework for Australian clinical quality registries. Sydney: Osteoarthritis of the Knee, 2014.

16. Tu JV, Willison DJ, Silver FL, et al. Impracticability of informed consent in the registry of the canadian stroke network. N Engl J Med 2004;350:1414-21.

17. Centre of Research Excellence in Patient Safety Department of Epidemiology and Preventive Medicine Monash University. Measuring Quality in Private Hospitals: Australian Centre for Health Research, 2008.

18. Australian Institute of Health and Welfare. Stronger evidence, better decisions, improved health and welfare. http://meteor.aihw. gov.au/content/index.phtml/itemld/181162 (accessed $28 \mathrm{Apr}$ 2017).

19. Buyurgan N, Rardin RL, Jayaraman R, et al. A novel GS1 data standard adoption roadmap for healthcare providers. Int $J$ Healthc Inf Syst Inform 2011;6:42-59.

20. Pusic AL, Chen CM, Cano S, et al. Measuring quality of life in cosmetic and reconstructive breast surgery: a systematic review of patient-reported outcomes instruments. Plast Reconstr Surg 2007:120:823-37.

21. Cooter RD, Barker S, Carroll SM, et al. International importance of robust breast device registries. Plast Reconstr Surg 2015;135:330-6.

22. Brown WA, Smith BR, Boglis M, et al. Streamlining ethics review for multisite quality and safety initiatives: national bariatric surgery registry experience. Med J Aust 2016;205:200-1.

23. Ludvigsson JF, Håberg SE, Knudsen GP, et al. Ethical aspects of registry-based research in the Nordic countries. Clin Epidemiol 2015;7:491-508.

24. Evans SM, Zalcberg JR. Enough is enough ... a call to action to improve ethical and governance review processes in Australia. Intern Med J 2016;46:1362-4. 